\title{
A Study on the Anti-preemptive Usages of Person Deixis-Taking Instances from Cyber Language
}

\author{
Hongya Fan \\ School of Foreign Languages, Shanxi University, Shanxi, China \\ Rui Song \\ School of Foreign Languages, Shanxi University, Shanxi, China
}

\begin{abstract}
Although numerous researches have been conducted to probe into the anti-preemptive usages of person deixis, few researches have been carried out on that of cyber languages. Therefore, this paper mainly investigates the anti-preemptive usages of person deixis in cyber language, collects the linguistic data of buyers and sellers on Taobao and the discursive practices posted on Weibo, and analyses the pragmatic functions of the anti-preemptive usages of person deixis with relevant pragmatic theories. The study applies the egocentricity of deixis as theoretical framework and makes a comprehensive analysis of the data, aiming to provide a new perspective for the study of deixis. The study yields four influencing factors of anti-preemptive usages of person deixis: lack of deictic context, pragmatic intention of the speaker, social factors and register factors. This paper bears both theoretical and practical values. Theoretically, it is an empirical attempt to the study on anti-preemptive usages of person deixis in the field of computer-mediated communication. From a practical point of view, the findings of the study are conductive to provide interlocutors with guidance on the use of person deixis whether in virtual context or real life communication.
\end{abstract}

Index Terms - deixis, anti-pre-emptive, cyber language

\section{INTRODUCTION}

Cyber language, the language on the Internet, is not only the carrier but also an important part of network culture. In recent years, with the rapid development of the Internet, the business industry based on the Internet has been booming. Taobao, a new online shopping mode in China, has emerged. It gradually accounts for a large part of people's daily life and is deeply loved by people. More and more people do shopping on Taobao and the communication between buyers and sellers becomes more frequent. Language is the reflection of the times. To some extent, network language is also the reflection of the current "network age", which is closely related to people's living style and the mode of thinking. For example, Taobao Style_ _ sellers often use friendly and lovely language to communicate with buyers, which shortens the distance between buyers and sellers. Taobao Style has played an important role in promoting the relationship between the two sides and building a bridge of mutual benefit. Of course, there will also be language conflicts between buyers and sellers, such as Taobao bad reviews.

In addition, both buyers and sellers use deixis frequently when they write comments or reply comments. Deixis is a technical term (from Greek) for one of the most basic things we do with utterances. It means 'pointing' via language. Any linguistic form used to accomplish this 'pointing' is called a deictic expression. Deixis involves person deixis, place deixis, time deixis, discourse deixis and social deixis (Fillmore, 1997).

Deixis has a common property of pre-emptiveness, which refers to forestalling deixis in advance of non-deictic expressions in certain contexts. However, in some specific contexts, there exists the phenomenon of replacing deixis with non-deictic words. This phenomenon is called anti-preemptive usage, that is, the pre-emptiveness disappears. In recent years, many scholars at home and abroad have studied the anti-preemptive phenomenon of deixis, but few scholars have combined the research of deixis with cyber language. This paper collects the linguistic data of buyers and sellers on Taobao and the discursive practices posted on Weibo, analyses the pragmatic functions of anti-preemptive usages of person deixis with relevant pragmatics theory, and provides a new perspective for the study of deixis.

More specifically, the research question is addressed as follows: What are the pragmatic functions and the influencing factors of the anti-preemptive usage of person deixis used in cyber language?

This paper is composed of five parts: introduction, literature review, theoretical framework, data analysis and summary. The first part is a general introduction to the whole paper, including research background, purpose and significance of this paper. The second part is a review of existing research on deixis, especially on the anti-preemptive usages of person deixis. The third part introduces the theoretical framework adopted in the study. The forth part makes an analysis of anti-preemptive usages of person deixis in cyber language, and yields four influencing factors of anti-preemptive usages of person deixis. The last part summarizes the full text and puts forward the shortcomings and future research directions. 


\section{LITERATURE REVIEW}

Deixis is a technical term (from Greek) for one of the most basic things we do with utterances. It means 'pointing' via language. As early as in 1940s, Russell has noticed the priority of deixis over non-deictic words in natural language, and he gave an example to illustrate this phenomenon. He supposed he was lost with his friend in the dark and they could not see each other, so the friend asked: "where are you?" He would respond: "I'm here", instead of answering in an exact and scientific way like "Russell is at latitude 53.16'N and longitude 4.03'W" (cited from Liu Hong, 2004). Lyons (1977) found that children in English speaking countries master tense and deictic adverbs before they master non-deictic expression, i.e. calendrical time and clock time. Fillmore (1975) pointed out that the prior usages of deixis can eliminate the ambiguity in some expressions. Afterwards, Levinson coined the term pre-emptive in 1983 when he was studying the projection nature of time deixis. He said: "Perhaps this pre-emptive nature of pure deictic words is a general tendency: it takes special conventions to make it appropriate for a speaker to refer to himself by name, and it would be strange to say 'Do it at 10:36' instead of 'Do it now', when now is 10:36' (Levinson, 2001, p.75).

However, Levision only put forward the term pre-emptive, but did not carry out a systematic explanation and in-depth study. In 1994, a Chinese professor Zhang Quan makes some researches on the preemptive nature of deixis and put forward another term "anti-preemptive usage" to refer to the phenomenon of non-deictic words substituting deixis, or in his words is the "disappearance of preemptive usage of deixis" (Zhang Quan, 1994, p.10. cited from Hao Xueling, 2016). After that, more researches are carried out into this phenomenon.

Researches on anti-preemptive phenomenon mainly focus on the cause, pragmatic function and English-Chinese comparison of this phenomenon based on the adaptation theory, accessibility theory and so on. In addition, some scholars investigate person deixis in special contexts, such as court discourse and real people show.

Zhang Quan (1994) explores the property of the pre-emptive phenomenon and factors restricting the pre-emptive phenomenon. In addition, by presenting pre-emptive examples in Chinese, he points out that in certain contexts, the pre-emptive phenomenon will disappear and the anti-preemptive phenomenon will occur.

Yang $\mathrm{Li}$ (2011) explores the process and causes of the anti-preemptive phenomenon of personal deixis in communicative context and linguistic context from the perspective of adaptation theory, and points out the importance of the anti-preemptive usage to achieve successful communication.

From the perspective of pragmatic cognition, Tang Ying (2010) tries to provide a reasonable mechanism for the pre-emptive phenomenon of deixis, taking the Ariel's accessibility theory and the egocentricity of deixis as the theoretical framework. She also examines the pragmatic factors that cause the anti-preemptive phenomenon.

Liu Chenghua (2006) expounds the pragmatic value of the anti-preemptive usage of person deixis with a large number of Chinese linguistic data. Jia Hui (2008) and Cao Lili (2013) further discuss and analyze the anti-preemptive phenomenon by enumerating English person deixis.

Lin Yingying (2013) studies the pragmatic factors that cause the anti-preemptive phenomenon under the guidance of context adaptation theory.

Zhao Hongwei (2006) analyzed the similarities and differences between English and Chinese about the pre-emptive and anti-preemptive usages of personal deixis, and then analyzes the role of such phenomena in the process of English-Chinese and Chinese-English translation.

Through the analysis of lawyer's defense statements, Li Bing (2015) finds that the anti-preemptive phenomenon exists in personal deixis, time deixis and place deixis. The anti-preemptive phenomenon of deixis is not only a linguistic form, but also a pragmatic strategy. It is a linguistic choice made by lawyers in order to adapt to specific contexts and achieve certain communicative purposes.

Peng Shan (2015) discusses the pre-emptiveness and anti-pre-emptiveness of deictic expressions in court context, which requires high accuracy of language expression. The result shows that the pre-emptive usage of deictic expressions in courtroom interaction slightly differs from it in daily communication, but the anti-pre-emptive usage of deictic expressions shows a higher rate to appear in courtroom discourse.

By analyzing the utterances between adults and children in speaker's perspective of subjectivity in the real people show_Dad, where are we going (2013), Hao Xueling(2016) compares and analyzes preemptive and anti-preemptive usages of person deixes and finds that the frequency of preemptive usages is higher than anti-preemptive usages.

\section{THEORETICAL FRAMEWORK: THE EgOCENTRICITY OF DEIXIS}

Austrian psycholinguist Buhler K's deictic field theory (1990) has a far-reaching influence on the history of deictic research. In his classic work Deixis Field and Deixis, Buhler puts forward the research questions and basic theories of deixis, and points out that deixis field is the here-now-I system of subjective orientation in speech acts.

Later, many scholars followed Buhler's "here-now-I" system and acknowledged that deixis has self-centered characteristics. Russell B.(1983, p.102-103) calls deixis "egocentric particulars" in his book Human Knowledge. He believes that the meaning of egocentric particulars varies with the change of the speaker and his location in time and space. Four basic egocentric particulars are "I", "this", "here" and "now". "Every time I use the word 'now', I mean a different point in time; every time I move, the word 'here' represents a different place; and when different people say the word 'I', it represents different person. 'This' and 'that' are obviously self-centered words. We can say 'I' means 
'the person who has experienced 'this' event, 'now' means 'this time', 'here' means 'this place'. If we know the speaker and the time, there is no ambiguity of the word 'this'. But if we don't know the person and the time, we don't know what it means." (Cited from Yu Xiaoxia, 2005, p.101-103)

Lyons pointed out that the typical context is ego-centered. The speaker regards himself as ego and everything is narrated from his own point of view. He is at "origo" of the space-time coordinate of context (Cited from Sun Lei, 2002, p.73).

Generally speaking, deixis is organized in an egocentric way. That is, unless otherwise stated, the deictic center is assumed to be as follows: (i) the central person is the speaker, (ii) the central time is the time at which the speaker produces the utterance, i.e. CT, (iii) the central place is the speaker's location at CT, (iv) the discourse center is the point which the speaker is currently at in the production of his utterance (Levinson, 2001, p.63-64). The closer the deixis is to the deictic center, the more likely it is in pre-emptive usage. For example, "today" is seldom used in a coding time, while "the day after tomorrow" is more likely to be replaced by a coding time. However, in some cases, the usage of deixis will deviate from egocentricity, thus producing special connotative meaning. The egocentricity of deixis can help us understand the preemptive phenomenon of deixis and explain the anti-preemptive phenomenon.

\section{The ANALysis of ANTI-PREEMPTIVE UsAges of PERSON DeIXIS}

In pragmatics, pre-emptiveness refers to forestalling deixis in advance of non-deictic expressions in certain contexts. However, in some special contexts, there exists the phenomenon of replacing deixis with non-deictic words, which is called the anti-preemptive usage. In this chapter, the pragmatic functions of person deixis will be analyzed with relevant pragmatics knowledge based on the linguistic data of buyers and sellers on Taobao and the discursive practices posted on Weibo.

\section{A. Anti-preemptive Usages of Person Deixis}

1. Anti-preemptive usages of first person deixis

(1)亲, 感谢您支持小宅家哦, 很抱兼咱们的宝贝没有让您满意呢, 您的反馈是我们最大的动力, 咱们也会在 以后上新更多优惠又好用的宝贝给小伙伴们呢......

Dear Customer, thank you for supporting my Taobao shop Xiaozhaijia. I'm sorry that our commodity didn't satisfy you. Your feedback is our greatest motivation. We'll also give more preferential price and useful commodities to our friends in the future.

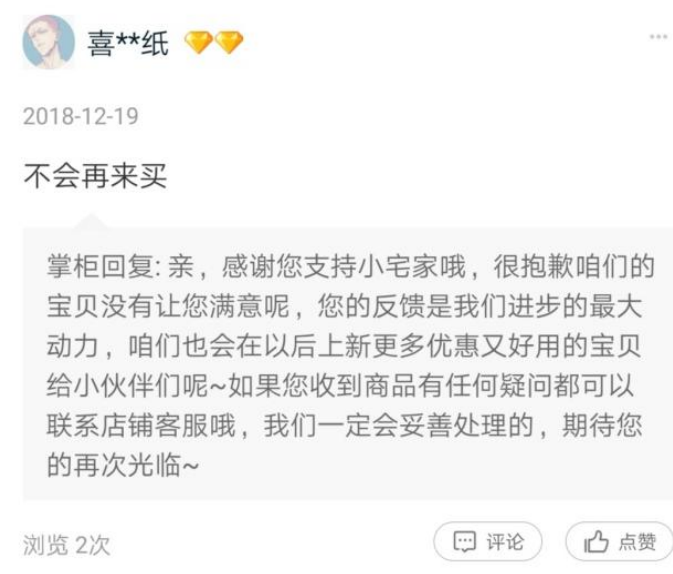

In this case, "Xiaozhaijia" is the anti-preemptive use of the first person deixis "we", which can shorten the psychological distance between the seller and the buyer, showing the intimacy of the seller's language. In addition, the social deixis "dear Customer" and the plural form of first person deixis "our" also show a gracious attitude, so that the buyer may have a good shopping experience. The first person deixis "our" here merely refers to "me" or "I", but it has the function of pragmatic empathy. From the perspective of pragmatics, the seller violates egocentricity of deixis, i.e. does not regard himself as the deixis center, and speaks from the buyer's point of view. In this way, the social relationship has been improved, and the communication has been promoted. Therefore, the personal deixis "our" also has the communicative function of social deixis.

(2).....商家态度极其恶劣, 对客户进行人身攻击, 差评! ......

... The seller's attitudes are extremely bad, with personal attacks on customers, terrible!... 


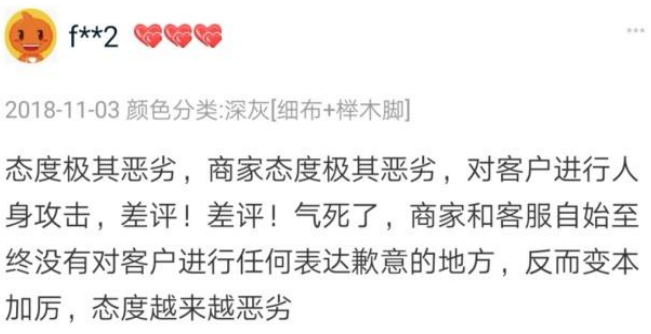

In this case, the buyer uses the word "customers" to refer to "I", expressing his or her power status by words, deliberately keeping the psychological distance from the seller, and showing his or her anger by the usage of pragmatic de-empathy. Ran Yongping (2007) first proposed the concept of "pragmatic de-empathy", which refers to the separation of emotion between the two sides of the communication. Instead of putting himself in the position of the addressee, the speaker deliberately expresses his attitude and emotion towards the addressee by some words. Ran Yongping (2007: 334) pointed out that the pragmatic de-empathy in interpersonal communication can reflect the emotional or psychological differences between the speaker and the addressee, thus create a psychological and social distance between the two parties.

(3)——我是个处女座, 追求完美。纸张很好, 快递太暴力。然后书脚坏掉了。所以....物流给三颗星。 好吧, 本处女座原谅一切。

I am a Virgo who pursues perfection. Paper is good, but express delivery is too violent. The corner of the book was broken. So... logistics is only worth three stars.

Well, I, a Virgo, forgive everything.

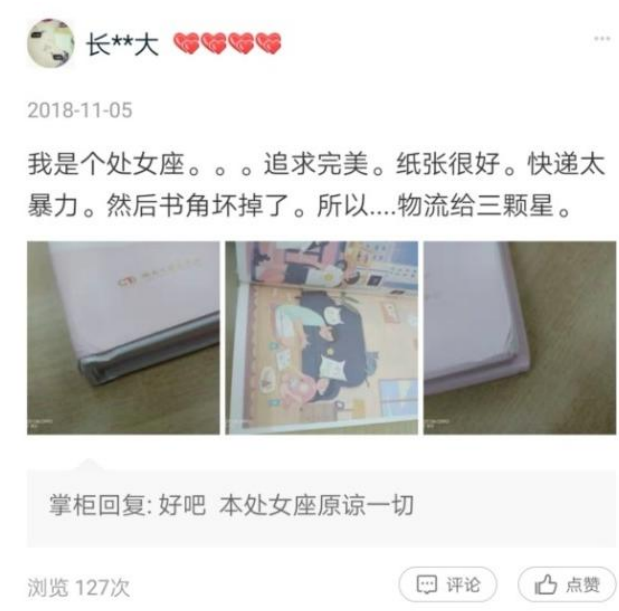

In Example (3), the buyer uses "Virgo" to refer to "I", suggesting that I am a Virgo like you, but you cannot forgive the mistake which "I" can forgive, using the irony in the words to express his dissatisfaction.

2. Anti-preemptive usages of second person deixis

(4)多谢小姐姐的支持呦么么哒

Thank you for your support, lass. Mua.

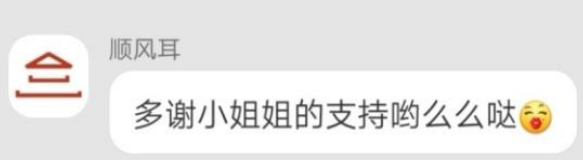

In this case, the seller replaces the second person deixis "you" with "lass", which is a popular Internet slang to describe tender and lovely girls. This address also shows a kind intimacy and shortens the psychological distance between the two sides.

(5) 一一我要的姨妈色和车厘子色，但给我发了一支不喜欢的颜色，真是不兢业！

我...... 㑣烦姐姐看清楚图片哈，姨妈色和车厘子色就是同一个颜色，都怪我没有及时看到你看错颜色了，都怪
I want brick-red and cherry-red, but the seller sent me a color I don't like. He is not conscientious!
notice that in time that you see the wrong color. I'm to blame... 


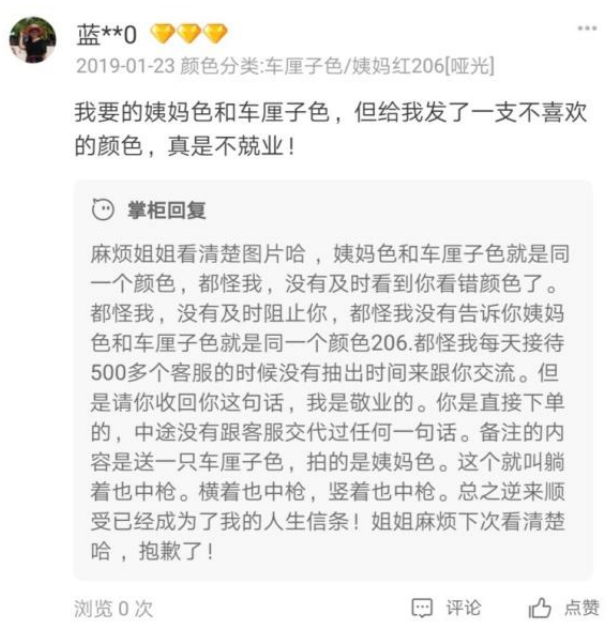

In Example (5), the seller uses the word "my sister" instead of the second person deixis "you", but here we can hear the satirical tone of the seller by analyzing the following series of parallel sentences and humorous words. It can be seen that the seller intentionally distances himself from the buyer and achieves the expected pragmatic effect.

3. Anti-preemptive usages of third person deixis

(6)一一收到货一个星期有了，洗了不知道是三次还是四次，掉色还是有点严重，烦死了 ......

一此人行为非常的不合理，手机号码一直是关机状态从没开机过，我们客服发过两次信息给他，消息都显 示已读了但一句话也没回复我们，还被他拉入黑名单了....

- I received the goods a week ago. I don't know whether it's washed three or four times, but the color fading is still a bit serious. I'm tired of it...

This person's behavior is very unreasonable. His mobile phone has been turned off and never turned on. Our customer service staff has sent him two messages. He read the message but replied no word to us. We were blacklisted by $\operatorname{him} . .$.

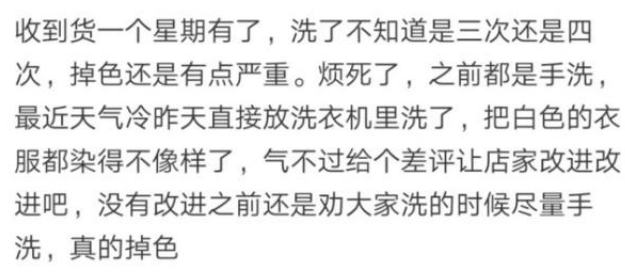

In this case, although the seller is responding to the comment, he regards the addressee as the other people who see this comment, and uses "this person" to refer to the third person deixis "he", which not only keeps the psychological distance with this buyer, but also expresses the reproach to the buyer. In this way, other people may empathize with the seller.

\section{B. The Influencing Factors of Anti-preemptive Usages of Person Deixis}

1. Lack of deictic context

A deictic word or expression can be used in three different ways: gestural, symbolic, and anaphoric. Gestural use means indicating something by body language and the addressee should be in the communication situation; by the symbolic use we merely need to know certain aspects of the speech communication situation; and the anaphoric use relates to other portion of the same discourse the expression is coreferential with (Fillmore, 1997). So the lack of deictic context can lead to the lack of deixis. For example, if a person you are not familiar with is knocking at the door and you ask "who is it", he or she will answer by name instead of "me". 
2. Pragmatic intention of the speaker

The speaker's pragmatic intention is often reflected in unconventional usages in discourses, and the anti-preemptiveness is one of them. The speaker often intentionally violates the egocentricity of deixis to shorten or keep the psychological or social distance between himself and the addressee in order to show friendship or indifference. In addition to pragmatic empathy and de-empathy, anti-preemptive usage can also achieve pragmatic effects such as humor, reproach, irony and so on. Several examples above illustrate this point.

3. Social factors

Social factors include social class and individual differences. For example, in order to show respect for the superiors, the rank or title is often used to replace the second person deixis "you", e.g. "Captain, this way, please!" The similar pragmatic usage also exists in cyber language. After the death of Jin Yong, who is a martial arts novelist, Ma Yun wrote on Weibo:

(7)先生其文也大，其人也真。 若无先生，不知是否还会有阿里。

Mr. Jin's writing is magnificent and he is a very real man...Without Mr. Jin, I wonder if there will be Ali.

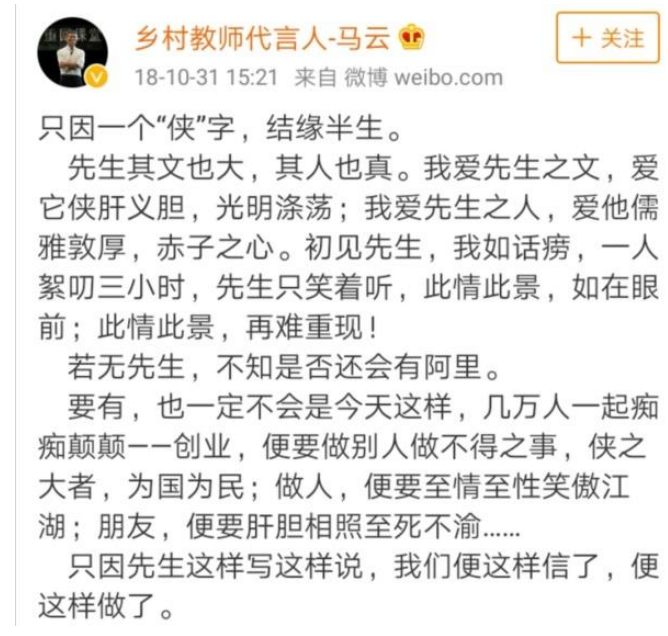

Ma Yun used the word "Mr Jin" instead of "you" to hold Mr. Jin in high esteem.

Individual differences are influenced by age, speech habits and so on. For example, children often use nicknames to refer to themselves.

4. Register factors

People use different languages in different occasions and for different addressees. Thus the anti-preemptive usage of personal deixis is common in formal occasions. For example, in news, the third person deixis is often replaced by the name directly. There are also anti-preemptive usages in cyber language influenced by register factors. The picture shows a statement issued by a Taobao store.

(8)本店遭遇同行商家高价雇佣请人到本店刷恶意差评.....

Our shop came across problems that people in the same line hired somebody at high price to write negative comments about our shop.

\section{本店遭遇同行恶意攻击}

本店遭遇同行商家高价雇佣请人到本店刷
恶意差评, 已经有两位亲承认是职业刷单
的, 是有人加他们Wei信, 接任务来给我
们差评, 一人能得三至五百。本店郑重承
诺, 此款卫衣保证是纯棉面料, 支持检验
假一赔百。如果真的出现起球掉色情况,
联系客服可退全款, 衣服也是不需奇回的
卫衣穿洗一年之内如果真的出现起球, 掉
色情况, 联系客服是能全额退款, 如果我
们做不到, 您再怎样评论我们都无话可说
真金不怕火炼 良心买卖, 真的只有真正的
好质量才敢如此保证。不义之财不要贪。
希望某些人不要再为了一己私利而去帮黑
心商家做事了。

The word "our shop" is written in formal style and used in a text similar to a notice. Thus, register factors are also one of the factors that cause the anti-preemptive usage of person deixis. 


\section{SUMMARY}

This paper analyses the pragmatic function of anti-preemptive use of person deixis with relevant pragmatics theory based on linguistic data from cyber language. Anti-preemptive use of person deixis in cyber language includes first person deixis, second person deixis and third person deixis. The result shows that the influencing factors of anti-preemptive use include 1) lack of deictic context, 2) pragmatic intention of the speaker in order to shorten or keep the psychological or social distance between himself and the addressee, 3) social factors which consist of social class and individual differences and 4) register factors. This paper still has some shortcomings: strong subjectivity and less linguistic data. It is hoped that future research will explore the pragmatic function of anti-preemptive phenomenon of person deixis based on more linguistic data in order to be more scientific. In addition, the study mainly investigates the anti-preemptive usage of person deixis in cyber language. Further research should explore the different usages of person deixis between the virtual world and real life.

\section{REFERENCES}

[1] Buhler, K. (1990). Theory of Language: The Representational Function of Language. Amsterdam: John Benjamins Publishing Company.

[2] Cao Lili. (2013). On the Anti-preemptive Phenomenon of Person Deixis in English. Modern Communication, 354, 48-49.

[3] Fillmore. (1997). C. J. Lecture On Deixis. California: CSLI Publications, Stanford.

[4] Hao Xueling. (2016). A Study on Preemptive and Anti-preemptive Usages of Person Deixis from Speaker's Perspective-Taking Instances from Dad, Where Are We Going (2013). Nanjing: Nanjing University of Science\&Technology.

[5] He Zhaoxiong. (2000). A New Introduction to Pragmatics. Shanghai: Shanghai Foreign Language Education Press.

[6] He Ziran. (1988). An Introduction to Pragmatics. Changsha: Hunan Education Press.

[7] He Ziran. (1991). Pragmatic Empathy in Verbal Communication. Foreign Language Teaching and Research, 4, 11-15.

[8] Jia Hui. (2008). An Analysis of the Anti-preemptive Phenomenon of Person Deixis in English. Knowledge Economy, 11, 156-157.

[9] Levinson, S. C. (2001). Pragmatics. Beijing: Foreign Language Teaching and Research Press and Cambridge University Press.

[10] Li Bing. (2015). A Study on the Adaptability of Anti-preemptive Usage of Deixis in Lawyer's Argument. Modern Chinese (Language Research Edition), 11, 82-84.

[11] Li Jie, He Ziran, Huo Yongshou. (2011). Twelve Lectures on Pragmatics. Shanghai: East China Normal University Press.

[12] Lin Yingying. (2013). A Study of Adaptation in Anti-preemptive Usage of English Person Deixis. Shanghai: East China Normal University.

[13] Liu Hong. (2004). A Study on Pre-emptive Use and Anti-pre-emptive Use of Deixis. Shanghai: East China Normal University.

[14] Liu Chenghua. (2006). The Anti-preemptive Phenomenon of Person Deixis in Modern Chinese. Rhetoric Learning, 6, 26-29.

[15] Lyons. J. (1977). Deixis and Anaphora. Luxembourg: European Union Press.

[16] Lyons. J. (1977). Semantics. Cambridge: Cambridge University Press.

[17] Peng Shan. (2015). A Study on Pre-emptive and Anti-Pre-Emptive Usage of Deictic Expression in Courtroom Discourse. Chongqing: Southwest University of Political Science and Law.

[18] Russell. (1983). Human Knowledge. Beijing: The Commercial Press.

[19] Ran Yongping. (2007). Pragmatic Perspectives, Pragmatic Empathy and De-empathy of Deixis. Foreign Language Teaching and Research, 5, 331-337.

[20] Stephen C. Levinson. (1983). Pragmatics. Cambridge: Cambridge University Press.

[21] Sun Lei. (2002). The History and Present Situation of Deixis Research in the Western Countries. Journal of Sichuan University (Social Sciences Edition), 6, 70-75.

[22] Tang Ying. (2010). On Pre-emptive and Anti-pre-emptive Usage of English Deictic Words. Shanghai: East China Normal University.

[23] Verschueren. (1999). Understanding Pragmatics. London: Edward Arnold.

[24] Yang Li. (2011). On the Anti-preemptive Phenomenon in English and Chinese Person Deixis. Contemporary Literature, 8, 193-194.

[25] Yu Xiaoxia. (2005). Egocentricity of Deixis and Deictic Projection. Journal of Qiqihar University (Philosophy and Social Sciences Edition), 1,101-103.

[26] Zhang Quan. (1994). The Preemptive Phenomenon of Deixis. Modern Foreign Languages, 2, 6-12.

[27] Zhao Hongwei. (2006). A Contrastive Study of the Pre-emptive Usage of Person Deixis in English and Chinese and the Translation. Journal of Anshun Teachers College, 1, 49-52.

Hongya Fan was born in Shanxi, China in 1974. She received her PH.D. degree in sociology from Nankai University, China in 2012.

She is currently an associate professor in the School of Foreign Languages, Shanxi University, Shanxi, China. Her research interests include pragmatics, discourse analysis and identity construction.

Rui Song was born in Shanxi, China in 1996. She is currently a postgraduate student in Shanxi University, majoring in Foreign Linguistics and Applied Linguistics. Her research interests include pragmatics and identity construction. 